\title{
Health Literacy: An Educationally Sensitive Patient Outcome
}

\author{
H. Shonna Yin, MD, MS $S^{1,2,4}$, Melanie Jay, $M D^{5,2,3,4}$, Leslie Maness, $B A^{7}$, Sondra Zabar, MD ${ }^{3,4}$, \\ and Adina Kalet, MD, MPH ${ }^{3,4}$
}

\begin{abstract}
'Department of Pediatrics, Division of General Pediatrics, New York University School of Medicine, New York, NY, USA; ${ }^{2}$ Department of Population Health, New York University School of Medicine, New York, NY, USA; ${ }^{3}$ Department of Medicine, Division of General Internal Medicine, New York University School of Medicine, New York, NY, USA; ${ }^{4}$ Research on Medical Education Research Unit, Program on Medical Education Innovation and Research, New York University School of Medicine, New York, NY, USA; ${ }^{5}$ Department of Medicine, Veterans Affair New York Harbor, New York, NY, USA.
\end{abstract}

We have previously proposed that by identifying a set of Educationally Sensitive Patient Outcomes (ESPOs), medical education outcomes research becomes more feasible and likely to provide meaningful guidance for medical education policy and practice. ESPOs are proximal outcomes that are sensitive to provider education, measurable, and linked to more distal health outcomes. Our previous model included Patient Activation and Clinical Microsystem Activation as ESPOs. In this paper, we discuss how Health Literacy, defined as "the degree to which individuals have the capacity to obtain, process, and understand basic health information and services needed to make appropriate health decisions, " is another important ESPO. Between one-third and one-half of all US adults have limited health literacy skills. Providers can be trained to adopt a "universal precautions approach" to addressing patient health literacy, through the acquisition of specific skills (e.g., teachback, "chunking" information, use of plain language written materials) and by learning how to take action to improve the "health literacy environment." While there are several ways to measure health literacy, identifying which measurement tools are most sensitive to provider education is important, but challenging and complex. Further research is needed to test this model and identify additional ESPOs.

KEY WORDS: medical education; health literacy; patient engagement; patient activation.

J Gen Intern Med 30(9):1363-8

DOI: $10.1007 / \mathrm{s} 11606-015-3329-\mathrm{Z}$

๑) Society of General Internal Medicine 2015

\section{INTRODUCTION}

The quality of medical education influences patient outcomes, but this relationship is difficult to study. ${ }^{1}$ We have proposed that by identifying a set of Educationally Sensitive Patient Outcomes (ESPOs), medical education outcomes research becomes more feasible and likely to provide meaningful guidance for medical education policy and practice. ${ }^{2}$

ESPOs are patient outcomes that are sensitive to provider education, can be measured, and are in the pathway linking medical education interventions to patient outcomes. As others have pointed out, conducting a series of studies which

Published online July 15, 2015 demonstrate these links can overcome many of the methodological complexities associated with attempting to directly link provider education to patient outcomes in a single study. ${ }^{3}$ ESPOs then become the most proximate patient outcome of provider education, but not the only one. Identifying a set of ESPOs will allow the medical education community to demonstrate return on investment in health professional education, and will provide more compelling guidance for critically important educational reform efforts. ${ }^{4,5}$

We have previously proposed Patient Activation and Clinical Microsystem Activation as ESPOs. Patient Activation is linked to health outcomes. ${ }^{6}$ Physician skills such as participatory decision making can lead to improved patient activation and better outcomes. ${ }^{7}$ Hibbard's Patient Activation Measure (PAM) has been shown to be a reliable measure, relatively easy to administer, and has been proposed as a health care quality measure. ${ }^{8-10}$ While more definitive study is needed, we have shown that measures of patient activating skills of residents in an Objective Structured Clinical Examination (OSCE) can identify residents more likely to promote actual weight loss in obese patients. ${ }^{11}$ Similarly, we have been able to demonstrate that trainees' lack of clinical microsystem awareness as assessed by unannounced standardized patients in actual clinical settings can threaten patient safety. ${ }^{12}$ Thus, the ESPO framework allows us to identify curricular interventions likely to lead to improvement in patient capacities directly related to important health outcomes. A number of ESPOs likely exist; health literacy is a good candidate. It can be measured, is associated with a range of health outcomes, and providers can be trained to improve a patient's measured health literacy.

\section{HEALTH LITERACY DEFINITION}

Health literacy is defined as "the degree to which individuals have the capacity to obtain, process, and understand basic health information and services needed to make appropriate health decisions. ${ }^{~} 13,14$ Health literacy encompasses the skills involved in all aspects of an individual's ability to address health-related issues, including their ability to read and understand written health information (print literacy), comprehend mathematical concepts such as risks/benefits of treatment choices (numeracy), listen to and understand spoken health 
information (oral literacy), and navigate the health care system (e.g., apply for insurance) ${ }^{15,16}$ Between one-third and onehalf of US adults have limited health literacy skills; ${ }^{14,17,18}$ racial/ethnic minorities, immigrants, the elderly, and low income groups are disproportionately affected. ${ }^{19}$

The link between health literacy and health outcomes is well established. Outcomes linked to limited health literacy include greater mortality and poorer global health status, increased hospitalizations, and emergency care use. ${ }^{20-24}$ Low health literacy is associated with worse asthma severity, poorer diabetic control, and obesity, ${ }^{22,23,25}$ and has been found to be a stronger predictor of outcomes than race/ethnicity, income, and education. ${ }^{25-27}$ Over the past decade, health literacy has come to be considered a critical quality and safety issue by the Institute of Medicine, ${ }^{14}$ Joint Commission, ${ }^{28}$ and the World Health Organization. ${ }^{29}$ In 2010, a National Action Plan was issued to tackle health literacy across sectors, including in education and research. ${ }^{30}$

\section{HEALTH LITERACY AS PART OF THE CLINICAL ENCOUNTER}

Professional organizations, including the American Medical Association, ${ }^{22,31}$ recognize that for patients to have improved outcomes, health literacy must be addressed as part of each clinical encounter. A "universal precautions" approach to the use of health literacy-informed provider-patient communication strategies is recommended, ${ }^{32}$ and includes use of plain language and avoidance of medical jargon, limiting counseling to 2-3 main concepts, and "chunking" of information into small digestible components. ${ }^{31,33-35}$ Advanced strategies include use of teachback/showback, drawings/pictures and supplementing verbal counseling with plain language written information. ${ }^{31,33,34}$ Teachback, which refers to having patients say in their own words what they understand, is a critical health literacy strategy. ${ }^{32,35,36}$ Showback may be especially effective when a patient is expected to undertake a specific task. For example, having a patient count out the number of daily pills, ${ }^{37}$ or demonstrate with oral syringe how much liquid medication will be given, ${ }^{38}$ can be helpful to ensure patient understanding.

Provider-centered health literacy-informed interventions have been associated with improved outcomes. We demonstrated that supplementing provider verbal counseling with low literacy, pictogram-based medication instruction sheets, along with demonstration, teachback/showback, and dosing tool provision, led to reduced parent dosing errors. ${ }^{38}$ Rothman et al. demonstrated that a disease management intervention involving plain language, teachback, and picture-based materials as part of 1:1 counseling sessions was associated with greater odds of achieving goal HbA1c levels. ${ }^{39}$ These studies support the use of provider-based approaches to tackling the problem of low health literacy.

\section{TEACHING HEALTH LITERACY SKILLS TO PHYSICIANS}

Unfortunately, providers do not regularly use health literacyinformed strategies in communicating with patients and their families. ${ }^{33,34}$ There is a clear need for health literacy training for both trainees and practicing providers; ${ }^{40-43}$ a recent study found that less than $50 \%$ of internal medicine residency programs included any formal teaching on health literacy. ${ }^{44}$ Over the past decade, there has been growing interest in incorporating health literacy concepts into the educational curriculum of trainees, including medical, nursing, pharmacy, and dietetic students. ${ }^{45-50}$

Numerous studies have demonstrated that health literacyinformed strategies can be taught and acquisition of skills can be measured. A range of teaching approaches have been used, including video tape review, small group discussions, and standardized patients. ${ }^{47,51-54}$ Trainees and providers attending workshops on health literacy-informed strategies report improved confidence in their abilities to assess and counsel patients. ${ }^{55,56}$ Provider participation in health literacy skillbuilding workshops improves provider skills and has a positive impact on patients, including greater patient confidence in medication management ${ }^{57}$ and ability to lose weight, ${ }^{58}$ increased preventive screening, ${ }^{59}$ and decreased healthcare utilization. ${ }^{57}$ Interprofessional educational interventions, including those that involve nursing ${ }^{60,61}$ and pharmacy ${ }^{39,50,62}$ groups, improve patient outcomes. Behaviorally anchored checklists used by observers of clinical and standardized patient encounters, are among the tools used to measure provider acquisition of health literacy skills. ${ }^{47,51,53}$

\section{MEASUREMENT OF HEALTH LITERACY IN PATIENTS}

For health literacy to be considered an ESPO, we must demonstrate improvements in patient health literacy measures. While some consider health literacy to be a "relatively fixed" stable trait, ${ }^{63}$ others consider it to be a more dynamic capacity that evolves with experience and context ${ }^{63-65}$ and is influenced by a multitude of factors, including their environment, physical/mental state, and their unique experience with a disease/condition.

Determining how to best measure patient health literacy is complex. Currently, "proxy" measures focused largely on patient understanding of written information are used. Commonly used assessments include the Test of Functional Health Literacy in Adults (TOFHLA) ${ }^{66}$ and the Rapid Estimate of Adult Literacy in Medicine (REALM) ${ }^{67,68}$ which have served as the foundation for the vast number of studies linking low health literacy to poor health knowledge, behaviors, and outcomes. It is well-recognized, however, that these tests do not capture the full spectrum of an individual's health literacy, which extends beyond understanding of written information to include an individual's oral literacy and navigational skills. The limited scope of existing assessment tools may explain why few studies have been able to demonstrate measurable 
improvements in scores. ${ }^{61,69}$ Improvements in diseasespecific health knowledge or health behavior are more likely to show demonstrable change after intervention, ${ }^{62,70,71}$ changes in knowledge alone may not necessarily lead to behavior change due to social and environmental barriers faced by patients. Ultimately, understanding which aspects of health literacy are sensitive to provider education will be crucial to determining the utility of health literacy as an ESPO in medical education research. It has been challenging to examine, within a single study, how provider training in health communication skills links to improved patient outcomes. An alternative approach is to use an ESPO framework to explore measures in relevant steps, as shown in Fig. 1. Significant research has already demonstrated links between individual steps toward patient outcomes. ${ }^{25,33,34,38,39,47,56,58,62,72-75}$

\section{HEALTH LITERACY, PATIENT ACTIVATION, AND THE CLINICAL ENVIRONMENT}

The construct of health literacy is very much intertwined with patient activation, which we previously proposed as an ESPO. Patients with low health literacy are known to be more reluctant to ask questions in the clinical setting, ${ }^{76}$ and low health literacy has been associated with worse patient activation scores. ${ }^{77}$ There is debate about whether health literacy is solely a skills-based construct for health self-management, or if it more broadly encompasses "activation" or motivation to manage one's health. ${ }^{78}$ Notably, the framework used to design health literacyinformed interventions targets learning stimulation and motivation (in concert with issues of literacy demand, graphics, and layout/typography), ${ }^{79}$ recognizing that patient engagement in the learning process is likely to be a key contributor to the ability to understand as well as act on health recommendations. While closely related, studies suggest that patient activation and health literacy are likely to be distinct constructs that influence health outcomes in different ways and that addressing both constructs will yield better long-term results. ${ }^{78}$ While the domain of patient activation centers primarily on motivation, the focus of the field of health literacy has been on presenting health information and designing health care systems in a way that facilitates the acquisition of knowledge and skills, as a means to activate and engage patients and their families. Consideration of health literacy as an ESPO would define an evidence base for a provider-patient health literacy communication skills curriculum and delineate specific assessment measures.

The relationship between health literacy and the health literacy environment parallels the relationship between patient activation and our other previously proposed ESPO, clinical microsystem activation. The concept of the health literacy environment acknowledges the commonly accepted broad view of health literacy, in which patients' understanding and actions are influenced by the clinical setting and the attitudes and actions of everyone involved in patient care. ${ }^{80,81}$ While there has been limited evidence to date establishing a causal link between measures of "health literacy environment" and poor health outcomes, research is underway. Tools to measure adequacy of the "health literacy environment" can be found in the AHRQ's Health Literacy Universal Precautions Toolkit, ${ }^{32}$ as well as Rudd's Health Literacy Environment Review. ${ }^{80}$

\section{THE CONCEPTUAL MODEL}

As a result of the above, we have added Health Literacy to a framework aimed at guiding medical educators and

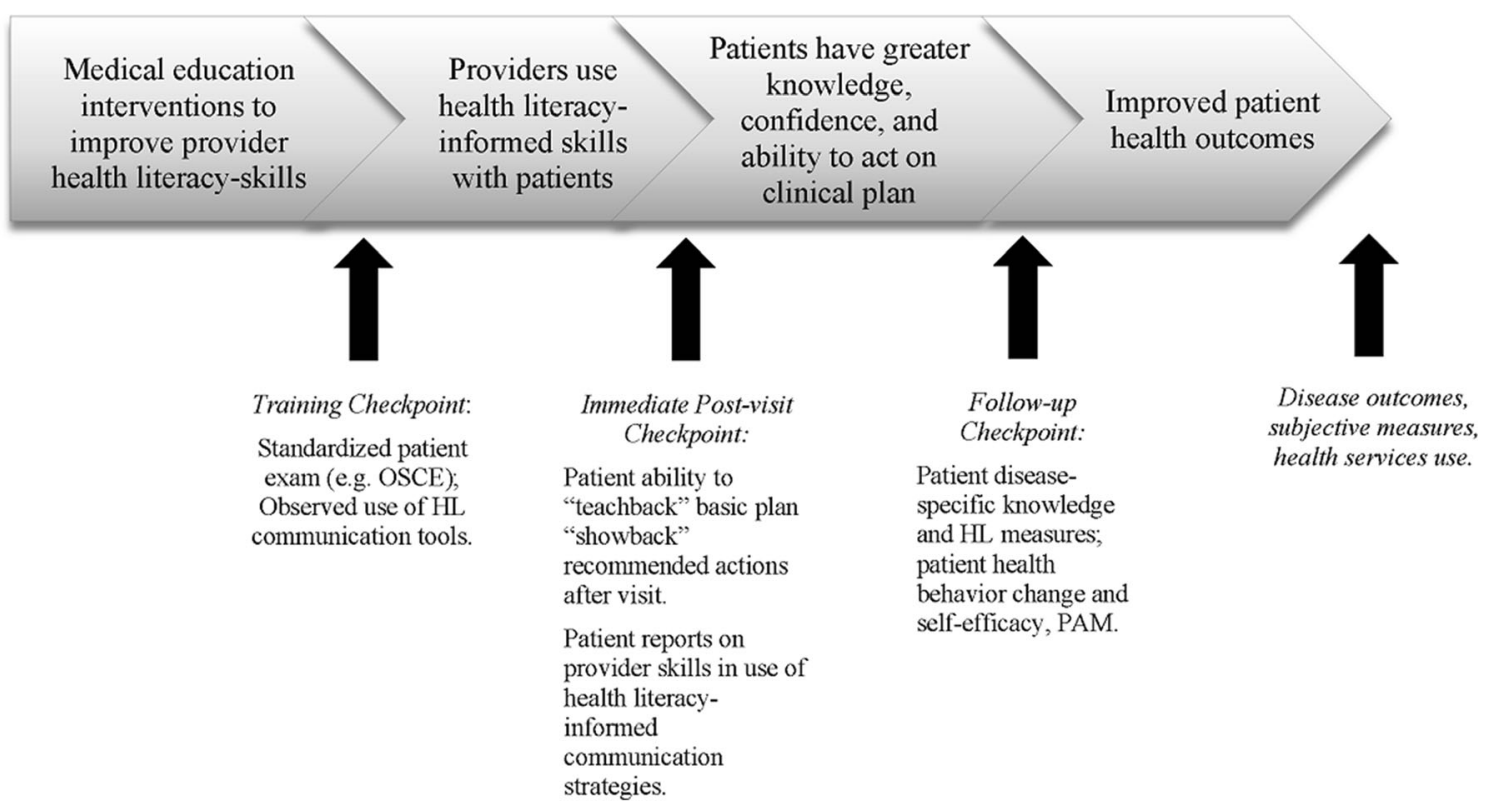

Figure 1. Proposed measurable health literacy-related outcomes: from medical education intervention to improved patient health. 


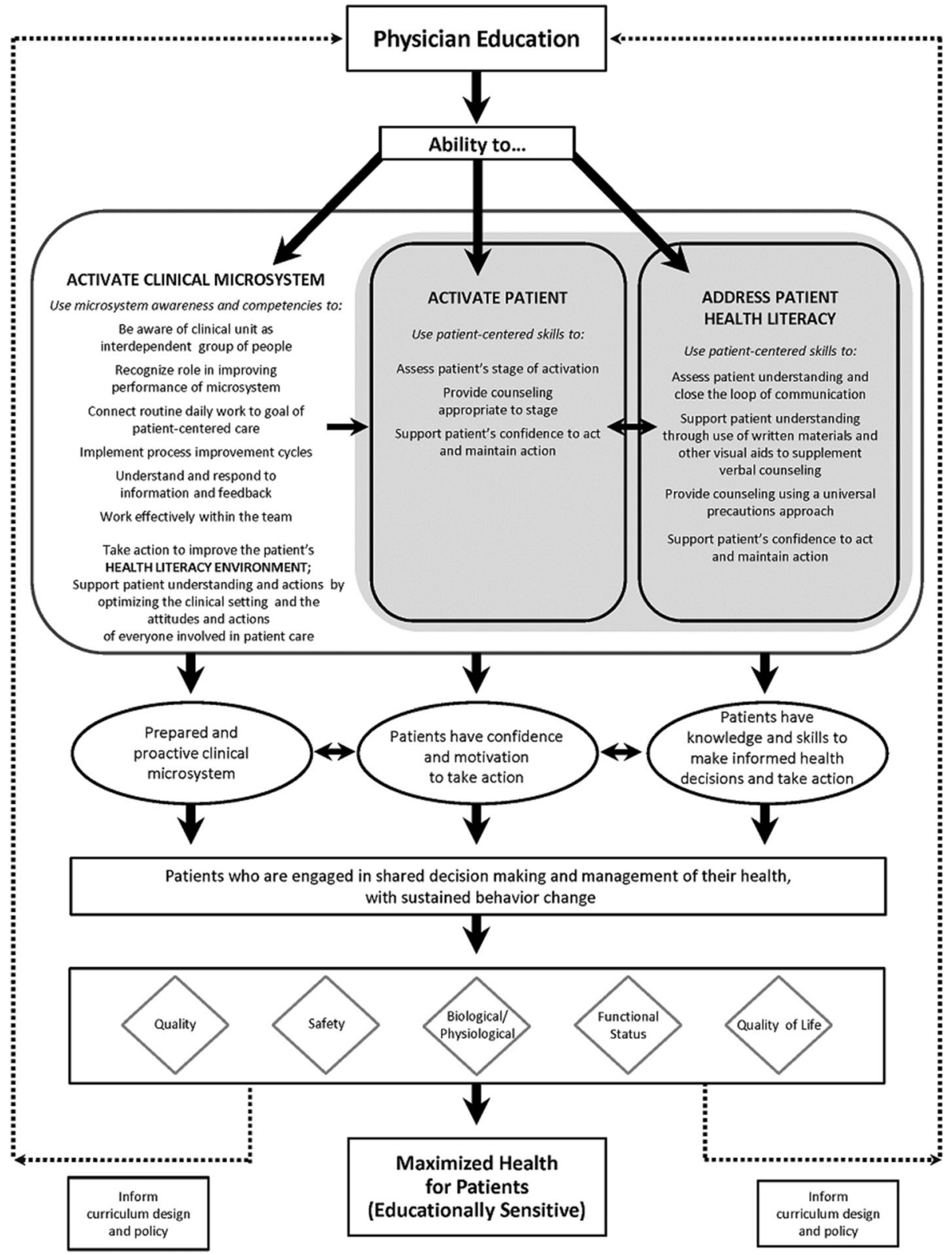

Figure 2. Educationally sensitive patient outcomes (ESPOs). Physician education leads to improved patient outcomes via the provider's use of strategies to activate the patient in their own self-care and ensure adequate health literacy. This education also ensures the clinician can activate the clinical microsystem to be a supportive health literacy environment.

researchers in the design and study of health professions education (Fig. 2). We fully acknowledge that the potential impact individual providers can have on an individual patient's health is limited and that a range of other important factors play a role (e.g., genetics, environmental, educational, socioeconomic, health system). We assert in this model, however, that there are a set of meaningful, temporally immediate patient outcomes that are sensitive to provider education and strongly linked to important health outcomes - in particular for those chronic diseases where sustained health promoting patient behavior is critical. We note that this framework is inextricably embedded in models of provider competence, health behavior change, chronic disease management, and health care quality and safety.

\section{CONCLUSION}

Health Literacy is an important potential ESPO. Research that leverages the rapidly amassing set of medical education and clinical data and incorporates the use of informatics based strategies ${ }^{82}$ is needed to explore the nature of the links between educational interventions, provider skill acquisition, and the influence on patient capacities such as health literacy that are most strongly connected to improved health outcomes. With the help of a medical ontologist and a computational biologist, we are doing foundational work to map the links among data sets of measures of physician competence, patient care processes, and contexts to test our proposed ESPOs model. 
To build a rich and valuable evidence base to guide society's investment in health professions education, we must identify and explore the links between medical education and the population's health. In this paper, we make the case that health literacy is worth considering as an important ESPO.

Acknowledgements: This work has been funded by a Human Resources Services Administration Bureau of Health Professions Academic Administrative Unit grant (HRSA\# D54HP05446 PI Zabar). We thank Jennifer Keane, Nina Song and Sarita Kundrod for administrative support.

Conflicts of Interest: The authors declare that they do not have a conflict of interest.

Corresponding Author: Adina Kalet, MD, MPH; Department of Medicine, Division of General Internal Medicine New York, NY 10016, USA (e-mail: Adina.Kalet@nyumc.org).

\section{REFERENCES}

1. Asch DA, Nicholson S, Srinivas SK, Herrin J, Epstein AJ. How do you deliver a good obstetrician? Outcome-based evaluation of medical education. Acad Med. 2014;89:24-6.

2. Kalet AL, Gillespie CC, Schwartz MD, et al. New measures to establish the evidence base for medical education: identifying educationally sensitive patient outcomes. Acad Med. 2010;85(5):844-51.

3. Cook DA, West CP. Perspective: reconsidering the focus on "outcomes research" in medical education: a cautionary note. Acad Med. 2013;88:162-7.

4. Cooke M, Irby DM, O'Brien BC. Educating physicians: a call for reform of medical school and residency. Vol 16: John Wiley \& Sons; 2010.

5. Asch DA, Weinstein DF. Innovation in medical education. NEJM. 2014;371(9):794-5.

6. Mosen DM, Schmittdiel J, Hibbard J, Sobel D, Remmers C, Bellows J. Is patient activation associated with outcomes of care for adults with chronic conditions? J Ambul Care Manag. 2007;30(1):21-9.

7. Parchman ML, Zeber JE, Palmer RF. Participatory decision making, patient activation, medication adherence, and intermediate clinical outcomes in type 2 diabetes: a STARNet study. Ann Fam Med. 2010;8(5):410-7.

8. Hibbard JH, Stockard J, Mahoney ER, Tusler M. Development of the patient activation measure (pam): conceptualizing and measuring activation in patients and consumers. Health Serv Res. 2004;39(4p 1): 1005-26.

9. Hibbard $\mathbf{J H}$, Greene $\mathbf{J}$. What the evidence shows about patient activation: better health outcomes and care experiences; fewer data on costs. Health Aff. 2013;32(2):207-14.

10. Hibbard JH, Greene J, Overton V. Patients with lower activation associated with higher costs; delivery systems should know their patients' 'Scores'. Health Aff. 2013;32(2):216-22.

11. Gillespie CC, Jay M, Schlair S, Zabar S, Kalet A. Resident physicians' patient activating skills are associated with obese patients' weight loss. J Gen Intern Med. 2011;26(Sup1):285.

12. Zabar S, Hanley K, Altshuler L, et al. Do clinical skills assessed in osces transfer to the real world of clinical practice? using unannounced standardized patient visits to assess transfer. Acad Med Med Ed. Under Rev. 2014.

13. Healthy People 2010. Understanding and improving health. 2nd ed. Washington: US Department of Health and Human Services; 2000. https: / /www.healthypeople.gov/2010/Document/pdf/Volume1/ 11HealthCom.pdf. Accessed 20 April 2015.

14. IOM. Health literacy: a prescription to end confusion. Washington: National Academies Press; 2004.

15. Parker RM, Williams MV, Weiss BD, et al. Health literacy-Report of the Council on Scientific Affairs. JAMA. 1999;281(6):552-7.

16. Baker DW. The meaning and the measure of health literacy. J Gen Intern Med. 2006;21(8):878-83.

17. Rudd RE. Health literacy skills of U.S. adults. Am J Health Behav. 2007;31(Supp 1):S8-18.

18. Kirsch IS. Adult literacy in america: a first look at the results of the national adult literacy survey. US Government printing office,
Superintendent of Documents. Washington: National Center for Education Statistics; 1993

19. Kutner M, Greenburg E, Jin Y, Paulsen C. The health literacy of america's adults: results from the 2003 national assessment of adult literacy. NCES 2006-483. Washington: National Center for Education Statistics, US Department for Education; 2006.

20. Berkman ND, Sheridan SL, Donahue KE, Halpern DJ, Crotty K. Low health literacy and health outcomes: an updated systematic review. Ann Intern Med. 2011;155(2):97-107.

21. Peterson PN, Shetterly SM, Clarke CL, et al. Health literacy and outcomes among patients with heart failure. JAMA. 2011;305(16):16951701.

22. Schwartzberg JG, VanGeest JB, Wang CC. Understanding health literacy: implications for medicine. 2005

23. Berkman ND, DeWalt DA, Pignone MP, et al. Literacy and health outcomes. Rockville: Agency for Healthcare Research and Quality, US Department of Health and Human Services; 2004. Evidence Report/ Technology Assessment No. 87.

24. Baker DW, Gazmararian JA, Williams MV, et al. Functional health literacy and the risk of hospital admission among Medicare managed care enrollees. Am J Public Health. 2002;92(8): 1278-83.

25. Berkman ND, Sheridan SL, Donahue KE, et al. Health literacy Interventions and outcomes: an updated systemic review. Rockville: Agency for Healthcare Research and Quality, U.S. Department of Health and Human Services; 2011. Evidence Report/Technology Assessment Number 199.

26. Osborn CY, Paasche-Orlow MK, Davis TC, Wolf MS. Health literacy: an overlooked factor in understanding hiv health disparities. Am J Prev Med. 2007;33(5):374-8.

27. Baker DW, Wolf MS, Feinglass J, Thompson JA, Gazmararian JA, Huang J. Health literacy and mortality among elderly persons. Arch Intern Med. 2007;167(14):1503-9.

28. What did the doctor say?: Improving health literacy to protect patient safety. Oakbrook Terrace, IL: The Joint Commission on Accreditation of Healthcare Organizations; 2007.

29. Kickbusch I, Pelikan JM, Apfel F, Tsouros AD. Health literacy: the solid facts. World Health Organization Regional Office for Europe; 2013. 9289000155.

30. National Action Plan to Improve Health Literacy. Washington, DC: US Department of Health and Human Services, Office of Disease Prevention and Health Promotion; 2010.

31. Weiss BD, Schwartzberg JG, Davis TC, Parker RM, Sokol PE, Williams Mv. Health literacy and patient safety: help patients understand manual for clinicians, Second edition. American Medical Association Foundation; 2007.

32. DeWalt DA, Callahan LF, Hawk VH, et al. Health literacy universal precautions toolkit. agency for healthcare research and quality, US Department of Health and Human Services; 2010.

33. Turner T, Cull WL, Bayldon B, et al. Pediatricians and health literacy: descriptive results from a national survey. Pediatrics. 2009;124(Supplement 3):S299-305.

34. Schwartzberg JG, Cowett A, VanGeest J, Wolf MS. Communication techniques for patients with low health literacy: a survey of physicians, nurses, and pharmacists. Am J Health Behav. 2007;31(Supplement 1):S96-104.

35. Abrams MA, Dreyer BP. Plain language pediatrics health literacy strategies and communication resources for common pediatric topics. AAP Books; 2008.

36. Schillinger D, Piette J, Grumbach $\mathbf{K}$, et al. Closing the loop: physician communication with diabetic patients who have low health literacy. Arch Intern Med. 2003;163:83-90.

37. Wolf MS, Davis TC, Shrank W, et al. To err is human: Patient misinterpretations of prescription drug label instructions. Patient Educ Couns. 2007;67(3):293-300.

38. Yin HS, Dreyer BP, van Schaick L, Foltin GL, Dinglas C, Mendelsohn AL. Randomized controlled trial of a pictogram-based intervention to reduce liquid medication dosing errors and improve adherence among caregivers of young children. Arch Pediatr Adolesc Med. 2008;162(9):814-22.

39. Rothman RL, DeWalt DA, Malone R, et al. Influence of patient literacy on the effectiveness of a primary care-based diabetes disease management program. JAMA. 2004;292(14):1711-6.

40. Bass PF III, Wilson JF, Griffith CH, Barnett DR. Residents' ability to identify patients with poor literacy skills. Acad Med. 2002;77(10):1039-41.

41. Lindau ST, Tomori C, Lyons T, Langseth L, Bennett CL, Garcia P. The association of health literacy with cervical cancer prevention knowledge and health behaviors in a multiethnic cohort of women. Am J Obstet Gynecol. 2002;186(5):938-43. 
42. Kelly PA, Haidet P. Physician overestimation of patient literacy: a potential source of health care disparities. Patient Educ Couns. 2007;66(1):119-22.

43. Price-Haywood EG, Roth KG, Shelby K, Cooper LA. Cancer risk communication with low health literacy patients: a continuing medical education program. J Gen Intern Med. 2009;25(Supplemental 2):126-9.

44. Ali NK. Are we training residents to communicate with low health literacy patients? J Community Hosp Intern Med Perspect. 2012;2(4).

45. Kripalani S, Weiss BD. Teaching about health literacy and clear communication. J Gen Intern Med. 2006;21(8):888-90.

46. Harper W, Cook S, Makoul G. Teaching medical students about health literacy: 2 chicago initiatives. Am J Health Behav. 2007;31(Supplement 1):S111-4.

47. Manning KD, Kripalani S. The use of standardized patients to teach lowliteracy communication skills. Am J Health Behav. 2007;31(Supplement 1):S105-10.

48. Coleman C. Teaching health care professionals about health literacy: A review of the literature. Nurs Outlook. 2011;59:70-8.

49. Cotugna N, Vickery CE. Health literacy education and training: A studentprofessional collaboration. J Am Diet Assn. 2003; 103:878-80.

50. Grice GR, Gattas NM, Sailors J, et al. Health literacy: use of the four habits model to improve student pharmacists' communication. Patient Educ Couns. 2013;90(1):23-8.

51. Price-Haywood EG, Harden-Barrios J, Cooper LA. Comparative effectiveness of audit-feedback versus additional physician communication training to improve cancer screening for patients with limited health literacy. J Gen Int Med. 2014:1-9.

52. Howard T, Jacobson KL, Kripalani S. Doctor talk: physicians' use of clear verbal communication. J Health Commun. 2013;18(8):991-1001.

53. Roberts DM, Reid JR, Conner AL, Barrer S, Miller KH, Ziegler C. A replicable model of a health literacy curriculum for a third-year clerkship. Teach Learn Med. 2012;24(3):200-10.

54. Sanders LM, Perrin EM, Yin HS, Bronaugh A, Rothman RL. "Greenlight study": a controlled trial of low-literacy, early childhood obesity prevention. Pediatrics. 2014; 133(6):e1724-37.

55. Perrin EM, Jacobson Vann JC, Lazorick S, et al. Bolstering confidence in obesity prevention and treatment counseling for resident and community pediatricians. Patient Educ Couns. 2008;73(2):179-85.

56. Kripalani S, Osborn CY, Vaccarino V, Jacobson TA. Development and evaluation of a medication counseling workshop for physicians: can we improve on 'take two pills and call me in the morning? Med Educ Online. $2011 ; 16$.

57. Clark NM, Gong M, Schork MA, et al. Impact of education for physicians on patient outcomes. Pediatrics. 1998;101(5):831-6.

58. Davis TC, Wolf MS, Bass PF, et al. Provider and patient intervention to improve weight loss: A pilot study in a public hospital clinic. Patient Educ Couns. 2008;72(1):56-62.

59. Ferreira MR, Dolan NC, Fitzgibbon ML, et al. Health care providerdirected intervention to increase colorectal cancer screening among veterans: results of a randomized controlled trial. J Clin Oncol. 2005;23(7):1548-54.

60. Bosworth HB, Olsen MK, Gentry P, et al. Nurse administered telephone intervention for blood pressure control: a patient-tailored multifactorial intervention. Patient Educ Couns. 2005;57(1):5-14.

61. Ntiri DW, Stewart M. Transformative learning intervention: effect on functional health literacy and diabetes knowledge in older african americans. Gerontol Geriatr Educ. 2009;30(2):100-13.
62. DeWalt DA, Malone RM, Bryant ME, et al. A heart failure selfmanagement program for patients of all literacy levels: A randomized, controlled trial [ISRCTN11535170]. BMC Health Serv Res. 2006;6(30).

63. Berkman ND, Davis TC, McCormack L. Health literacy: what is it? J Health Commun. 2010;15(S2):9-19.

64. Zarcadoolas C, Pleasant A, Greer DS. Understanding health literacy: an expanded model. Health Promot Int. 2005;20(2): 195-203.

65. Freedman DA, Bess KD, Tucker HA, Boyd DL, Tuchman AM, Wallston KA. Public health literacy defined. Am J Prev Med. 2009;36(5):446-51.

66. Parker RM, Baker DW, Williams MV, Nurss JR. The test of functional health literacy in adults: a new instrument for measuring patients' literacy skills. J Gen Intern Med. 1995; 10:537-41

67. Davis TC, Long SW, Jackson RH. Rapid estimate of adult literacy in medicine: a shortened screening instrument. Fam Med. 1993;25:39-5.

68. Haun JN, Valerio MA, McCormack LA, Sorensen K, Paasche-Orlow MK. Health literacy measurement: an inventory and descriptive summary of 51 instruments. J Health Commun: Int Perspect. 2014;19(sup2):302-33.

69. Allen K, Zoellner J, Motley M, Estabrooks PA. Understanding the Internal and External Validity of Health Literacy Interventions: A Systematic Literature Review Using the RE-AIM Framework. J Health Commun. 2011;16(Sup3):55-72.

70. Fitzgerald JT, Funnell MM, Hess GE, et al. The Reliability and Validity of a Brief Diabetes Knowledge Test. Diabetes Care. 1998;21(5):706-10.

71. Carey MP, Morrison-Beedy D, Johnson BT. The HIV-Knowledge questionnaire: development and evaluation of a reliable, valid, and practical self-administered questionnaire. AIDS Behav. 1997;1(1):61-74.

72. Osborn CY, Paasche-Orlow MK, Cooper Bailey S, Wolf MS. The mechanisms linking health literacy to behavior and health status. Am J Health Behav. 2011;35(1):118-28.

73. Clement S, Ibrahim S, Crichton N, Wolf M, Rowlands G. Complex interventions to improve the health of people with limited literacy: a systematic review. Patient Educ Couns. 2009;75(3):340-51.

74. Rao JK, Anderson LA, Inui TS, Frankel RM. Communication interventions make a difference in conversations between physicians and patients: a systematic review of the evidence. Med Care. 2007;45(4):340-9.

75. Zolnierek KBH, DiMatteo MR. Physician communication and patient adherence to treatment: a meta-analysis. Med Care. 2009;47(8):826-34.

76. Katz MG, Jacobson TA, Veledar E, Kripalani S. Patient literacy and question-asking behavior during the medical encounter: a mixed-methods analysis. J Gen Intern Med. 2007;22(6):782-6.

77. Lubetkin EI, Lu W-H, Gold MR. Levels and correlates of patient activation in health center settings: building strategies for improving health outcomes. J Health Care Poor Underserved. 2010;21(3):796-808.

78. Smith SG, Curtis LM, Wardle J, von Wagner C, Wolf MS. Skill set or mind set? associations between health literacy, patient activation and health. PloS ONE. 2013;8(9):e74373.

79. Doak CC, Doak LG, Root JH. Teaching patients with low literacy skills. Am J Nurs. 1996;96(12):16M

80. Rudd RE, Anderson JE. The health literacy environment of hospitals and health centers. Cambridge: National Center for the Study of Adult Learning and Literacy; Health and Adult Literacy and Learning Initiative, Harvard School of Public Health; 2006.

81. Rudd RE. The health literacy environment activity packet first impressions \& walking interview. 2010

82. Ellaway RH, Pusic MV, Galbraith RM, Cameron T. Developing the role of big data and analytics in health professional education. Med Teach. 2014;36(3):216-22. 